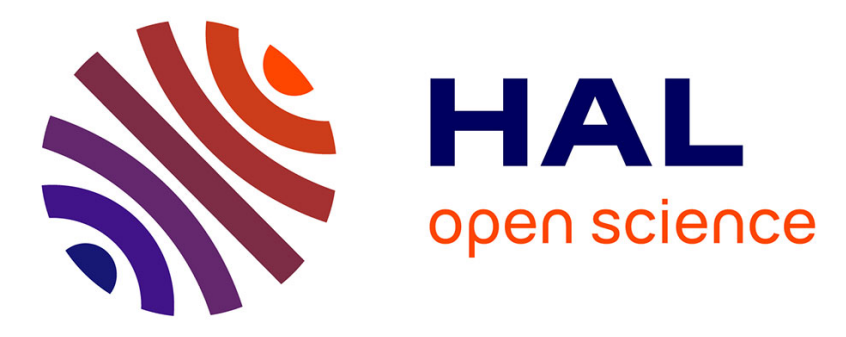

\title{
Population position along the fast-slow life-history continuum predicts intraspecific variation in actuarial senescence
}

Hugo Cayuela, Jean-François Lemaître Lemaître, Eric Bonnaire, Julian

Pichenot, Benedikt Schmidt

\section{To cite this version:}

Hugo Cayuela, Jean-François Lemaître Lemaître, Eric Bonnaire, Julian Pichenot, Benedikt Schmidt. Population position along the fast-slow life-history continuum predicts intraspecific variation in actuarial senescence. Journal of Animal Ecology, 2020, 89 (4), pp.1069-1079. 10.1111/1365-2656.13172 . hal-03060293

\section{HAL Id: hal-03060293 https://hal.science/hal-03060293}

Submitted on 14 Dec 2020

HAL is a multi-disciplinary open access archive for the deposit and dissemination of scientific research documents, whether they are published or not. The documents may come from teaching and research institutions in France or abroad, or from public or private research centers.
L'archive ouverte pluridisciplinaire HAL, est destinée au dépôt et à la diffusion de documents scientifiques de niveau recherche, publiés ou non, émanant des établissements d'enseignement et de recherche français ou étrangers, des laboratoires publics ou privés. 


\section{Population position along the fast-slow life-history continuum predicts 2 intraspecific variation in actuarial senescence}

3

4 Hugo Cayuela ${ }^{1}$, Jean-François Lemaître ${ }^{2}$, Eric Bonnaire ${ }^{3}$, Julian Pichenot ${ }^{4}$, Benedikt R. Schmidt ${ }^{5,6}$ 5

$6 \quad{ }^{1}$ Département de Biologie, Institut de Biologie Intégrative et des Systèmes (IBIS), Université

7 Laval, Pavillon Charles-Eugène-Marchand, Québec, QC G1V 0A6, Canada

$8 \quad{ }^{2}$ Université Lyon 1, CNRS, UMR 5558, Laboratoire de Biométrie et Biologie Evolutive, F-

9 69622, Villeurbanne, France

$10{ }^{3}$ Office National des Forêts, Agence de Verdun, route de Metz, 55100, Verdun, France

$11{ }^{4}$ URCA, CERFE, Centre de Recherche et Formation en Eco-éthologie, 08240, Boult-aux-Bois,

12 France

$13{ }^{5}$ Institut für Evolutionsbiologie und Umweltwissenschaften, Universität Zürich,

14 Winterthurerstrasse 190, 8057 Zürich, Switzerland, orcid.org/0000-0002-4023-1001

$15{ }^{6}$ Info Fauna Karch, UniMail, Bâtiment G, Bellevaux 51, 2000 Neuchâtel, Switzerland

16

17 Running title: Intraspecific variation in senescence

$18 \mathrm{HC}$ and BRS conceived the research questions. HC carried out the capture-recapture analyses and 19 drafted the manuscript. JFL and BRS contributed to writing the manuscript. EB and JP collected 20 field data. All authors gave final approval for publication.

21

22 Corresponding author: Hugo Cayuela, hugo.cayuela51@gmail.com

23

24 The data will be available on Dryad after paper acceptance. 
Most commonly accepted evolutionary theories of ageing posit that survival should decline with increasing age in any age-structured population (Hamilton 1966), a demographic process known as actuarial senescence. Medawar's (1952) mutation accumulation theory first stated that organisms age because the strength of natural selection weakens with age after first reproduction and therefore there is no purging of deleterious mutations that are only expressed late in life. In addition, actuarial senescence can emerge as a by-product of natural selection through antagonistic pleiotropy (Williams 1957). An allele may confer a benefit to the bearer early in life but may also be responsible for an impaired survival later in life. Finally, the disposable soma theory of aging postulates that actuarial senescence can result from a trade-off between allocation to reproduction in early life and somatic maintenance (Kirkwood 1977, Kirkwood \& Austad 2000). In other words, individuals that preferentially allocate resources to growth and/or reproduction (e.g., gamete production and parental care) will have much less resources for somatic maintenance (e.g., enzymebased repair mechanisms), which will ultimately lead to a decline in performance of fitness-related traits (e.g., survival) at advanced ages. So far, most studies focused on aging in the wild have been embedded within the two theoretical frameworks offered by both antagonistic pleiotropy and disposable soma theories of aging as these two theories share the similar prediction of a trade-off between reproductive effort and actuarial senescence (Gaillard \& Lemaître 2017).

Although a few case studies on free-ranging populations failed to detect any increase in mortality rate with age (Jones et al. 2014, Cayuela et al. 2019c), most recent syntheses revealed two major facts. First, actuarial senescence is a nearly ubiquitous process in the living world (Nussey et al. 2013, Shefferson et al. 2017). Second, patterns of senescence can be highly variable among species (Jones et al. 2014, Tidière et al. 2016, Colchero et al. 2019). Comparative analyses have shown that senescence patterns across multi-cellular organisms can be predicted by ecological traits, lifestyles and covariation among life-history traits (Péron et al. 2010, Ricklefs 2010, Gaillard et al. 2016, Salguero-Gómez \& Jones 2017). In particular, both age at the onset of senescence and rates of senescence appear to be linked to the position of a species along the fast-slow life-history

77 continuum. Organisms that occupy the fast end of the continuum - short generation time, high 78 annual fecundity, and low mean survival rates (Stearns 1983) - tend to experience earlier and faster 79 actuarial senescence than organisms at the slow end of the continuum (Jones et al. 2008a, Salguero80 Gómez \& Jones 2017). Since life history variation does not only occur among, but also within 81 species (Berven \& Gill 1983, Cayuela et al. 2017), intraspecific variation in senescence patterns is 82 expected and can be selected for (Stearns 2000, Stearns et al. 2000, Brommer et al. 2007, Holand 
senescence and the speed and the shape of the relationship between mortality rate and age) differed

118 between populations with slow and fast life histories. We focused our analyses on post-

119 metamorphic survival as we did not expect senescence during larval development and assumed that

120 senescence can begin once structural development is completed (i.e., metamorphosis). We expected

121 that the pattern of intraspecific variation in actuarial senescence among populations would be

122 similar to pattern in variation among species. Therefore, we tested the prediction that a fast pace-

123 of-life should be associated with an earlier, faster actuarial senescence among populations of $B$.

124 variegata.

125

Material and methods

Study system

Bombina variegata populations occur in different types of habitats where the spatiotemporal pattern of breeding resource availability differs widely. In riverine environments, the patches of rock pools used by toads to reproduce are constantly available in space and time, making breeding resources highly predictable at the scale of the lifetime of an individual. By contrast, rut patches resulting from logging operations appear and disappear stochastically in forests, making breeding resource availability unpredictable. The annual probability of patch appearance varies from 0.20 to 0.50 while the rate disappearance ranges from 0.05 to 0.20 , depending on the year and the population (Cayuela et al. 2016a).

Previous studies showed that the populations from these two types of environment have different life history strategies. Fast populations from forest environment have accelerated life histories, with lower postmetamorphic survival and higher fecundity than in riverine habitats.

141 Moreover, the fast life history is associated with higher dispersal (i.e., dispersal syndrome) caused 142 by the high patch turn-over resulting from logging operations (Cayuela et al. 2016c, 2019b).

143 Dispersal is facilitated by a phenotypic specialization that is transgenerationally transmitted: 144 individuals from fast forest populations reared in common garden have a higher boldness and 145 exploration propensity than those from riverine slow populations (Cayuela et al. 2019b). The 146 association between high dispersal maintained throughout lifespan, pre-natally determined 147 behavior, and accelerated life history (i.e., life history syndrome; Réale et al. 2010) is likely 148 determined by polygenic bases and gene with pleiotropic effects (Saastamoinen et al. 2018). 149 Furthermore, changes in dispersal regime within spatially structured populations of $B$. variegata 150 lead to strong variation in neutral genetic structure. Fast forest populations have a higher genetic 
pattern used to identify individuals is not fixed before that age. Yet, this method permits to survey the toads for the rest of their lives in a non-invasive way. Only individuals can be aged which are one or two years old at first capture (Cayuela et al. 2016b), leading to partially known birth date; this incomplete knowledge of age of individuals is handled using Bayesian survival trajectory analyses (see the section Capture-recapture modeling). Sex cannot be assessed with certainty before sexual maturity (2-3 years old) due to the lack of nuptial pads in immature males. For this reason, we did not include an effect of sex in the analyses. Yet, we expect that excluding sex from our analyses should not alter our conclusions since previous studies in these populations did not detect sex-specific effects on survival (Cayuela et al. 2016a, 2016c). Details about the number of survey years, individual age and sampling effort are provided in Appendix 1 (Table 2). A more complete description about the capture-recapture survey, the individual recognition method and population description can be found in Cayuela et al. (2016a, 2016c).

\section{Capture-recapture modeling}

We investigated actuarial senescence patterns using Bayesian survival trajectory analyses implemented in the R package BaSTA (Colchero et al. 2012a, 2012b). BaSTA allowed us to account for imperfect detection, left-truncated (i.e., unknown birth date (age)) and right-censored (i.e., unknown death date) capture-recapture data in our analysis. Our analyses focus on the postmetamorphic stage at which senescence is expected to occur (as in Colchero et al. 2019). BaSTA allows estimation of two parameters: age-dependent survival and the proportion of individuals dying at a given age (i.e. age-dependent mortality rate). Given the results of previous analyses (Cayuela et al. 2016a, 2016b), we allowed recapture probabilities to vary among years. As the study period and number of survey years differ among populations (Appendix 1), the four populations were analyzed separately. We used deviance information criterion (DIC) to select models that fitted the data best (Colchero et al. 2019) and we compared the outputs of the best-supported model of the four populations by inspecting mean estimates and 95\% credible intervals (CRI) (Anderson et al. 2001, Amrhein et al. 2019). This allowed us to investigate population-specific variation in the shape of the age-specific mortality patterns. We considered the four mortality functions implemented in BaSTA: exponential, Gompertz, Weibull and logistic. For the three last functions, we considered three potential shapes: simple that only uses the basic functions described above; Makeham (Pletcher 1999); and bathtub (Silver 1979). As individuals which are less than one year old cannot be individually recognized, we conditioned the analyses at a minimum age of one. Four MCMC chains were run with 50000 iterations and a burn-in of 5000. Chains were thinned by a 
253 after individuals are 2-3 years old and reached an asymptote at an age of 3 to 4 years. This suggests

254 an early, fast senescence with a short reproductive lifespan.

255 Age-dependent survival patterns were relatively similar between the populations with the 256 same life history strategies but differed markedly between strategies (Fig. 3). In slow populations

257 (Fig. 3A and 3B), the cumulative probability of surviving until a given age decreased slowly over

258 a toad's lifetime: it was 0.78 until age three, 0.43 until age six, 0.17 until age nine, and finally 0.00

259 until age 12 (Appendix 1, Table 2-3). In fast populations (Fig. 3C and 3D), cumulative survival

260 probability decreased rapidly after two years: it was 0.58 until age three, 0.07 until age six, and

2610.00 until age nine (Appendix 1, Table 4-5).

\section{Discussion}

265 We provide the first clear evidence for actuarial senescence in a wild amphibian that is associated 266 with an intraspecific slow-fast life history difference. The onset of actuarial senescence was earlier 267 in individuals from fast populations and individuals show a faster rate of actuarial senescence than individuals in slow populations.

Population viability, elasticity of demographic parameters, and potential confounding factors

272 Population matrix models showed that the four populations had population growth rates higher than

2731 and can therefore be considered to be viable. Moreover, we highlighted changes in the elasticity 274 of demographic rates: slow population have higher elasticities for adult survival and lower 275 elasticities for pre-breeding survival and fecundity than fast populations. Taken together, our results 276 suggest that life history acceleration in forest populations is not caused by an ongoing demographic 277 decline or transient dynamics. By contrast, variation in life history speed seems to rely on stable 278 demographic strategies covarying with behavioral syndromes that likely have genetic bases 279 (Cayuela et al. 2019b).

280 Although the habitat type (forest vs riverine) is confounded with latitude in our study 281 system, it is unlikely that the difference in latitude has an effect on demographic traits and actuarial 282 senescence. First, a previous study showed that climate has idiosyncratic effects on population 283 dynamics and there was no evidence for an influence of latitude on demographic rates in $B$. 284 variegata (Cayuela et al. 2016b). Second, populations with slow life history strategies occurring in 285 quarry habitats can be found in the northern part of the study area (Cayuela et al. 2019a), which 286 suggests that latitude is not an important predictor of demographic rates. Third, life history variation 
320 precise quantification of this onset) and had a faster rate of actuarial senescence than individuals

321 from slow populations.

322 In our study system, individuals from fast populations occurring in forest environment face

323 higher level of environmentally-driven mortality (associated with the unpredictability of breeding

324 patches) than individuals from the slow populations. In fast B. variegata populations, logging

325 management frequently lead to the destruction of breeding patches, which decreases adult survival

326 via direct mortality during harvesting operations (Cayuela et al. 2018). In addition, as the natural

327 silting of ruts decreases local breeding success over time, individuals frequently disperse to

328 colonize new patches and likely incur energy and mortality costs related to the different stages of

329 the dispersal process (i.e., emigration, transience, and immigration; Boualit et al. 2019, Cayuela et

330 al. 2019b). By contrast, slow populations occur in non-managed habitats with very limited human

331 activity where dispersal is virtually absent, which likely decrease environmentally-driven mortality

332 (Cayuela et al. 2019b). Since Williams (1957) pioneering contribution on this topic, the relationship

333 between environmentally-driven mortality and actuarial senescence has been heavily discussed (see

334 Gaillard \& Lemaître 2017 and Ronget et al. 2017 for reviews). According to Williams (1957), high

335 level of adult mortality should lead to a much stronger rate of actuarial senescence, a prediction

336 which was validated by simulations (Gaillard \& Lemaître 2017), at least in absence of density-

337 dependent or condition-dependent mortality over the entire life course (Abrams 1993, Williams \&

338 Day 2003; see also Moorad et al. 2019 for a recent review). For instance, if mortality during the

339 juvenile period is strongly condition-dependent, only the most robust individuals will reach

340 adulthood which can postpone and/or decrease actuarial senescence rates (Ronget et al. 2017). Such

341 information is currently lacking in B. variegata but would provide important insights on how

342 environmentally-driven mortality modulate the selective forces acting against actuarial senescence.

343 In our study system, actuarial senescence likely evolves from an adjustment of resource

344 allocation strategies in response to environmentally-driven mortality (Kirkwood \& Rose 1991;

345 Stearns 2000, Baudisch \& Vaupel 2012). In others words, individuals from the fast populations

346 might be able to cope with higher level of environmentally-driven mortality by allocating more

347 resources to reproduction at the expense of somatic maintenance (see Cayuela et al. 2016a, 2016b

348 for an in-depth discussion). This might ultimately lead to a faster decline in survival probabilities

349 of individuals with age, as expected under the disposable soma theory of ageing (Kirkwood \&

350 Austad 2000). In contrast, environmentally-driven mortality is lower in riverine environment where

351 the predictability of breeding patches is high and human activity is virtually inexistent.

352 Accordingly, individuals may allocate fewer resources to reproduction - females produce a lower

353 number of juveniles per year (Cayuela et al. 2016a) - and more to somatic maintenance, resulting 

2017), then phylogenetic constraints would be a weak explanation for senescence patterns across the tree of life (Antonovics \& van Tienderen 1991). Second, if there is intraspecific variation in senescence, this variation could explain the weakness of the phylogenetic signals in actuarial senescence patterns in several taxa (Salguero-Gómez \& Jones 2017). It may well be that phylogenetic signals could become more apparent once intraspecific variation is taken into account. Such a combination of microevolutionary and macroevolutionary patterns of senescence would lead to a deeper understanding of the evolutionary biology of senescence.

\section{Acknowledgments}

We thank all the field workers that have contributed to data collection and Erin Muths for her comments on the manuscript. This research was funded by the Lorraine DREAL, the Rhône-Alpes DREAL, the Agence de l'Eau Rhône-Alpes, the Agence de l'Eau Rhin-Meuse, the Office National des Forêts, the Conseil Régional de Lorraine, the Conseil Régional de Champagne-Ardenne, the Conseil Régional de Picardie, the Conseil Général de l'Aisne, the Conseil Général d'Ardèche, the Conseil Général d'Isère and the Communauté de Communes de l'Argonne Ardennaise (2C2A). Toad capture was authorized by the Préfecture de l'Ardèche (arrêté no. 2014-288-002) and the Préfecture de la Meuse (arrêté no. 2008-2150).

\section{References}

Abrams PA. 1993. Does increased mortality favor the evolution of more rapid senescence? Evolution, 47, 877-887. (doi: 10.1111/j.1558-5646.1993.tb01241.x)

Amrhein V, Greenland S, McShane B. 2019. Retire statistical significance. Nature 567, 305-307.

Anderson DR, Link WA, Johnson DH, Burnham KP. 2001. Suggestions for presenting the results of data analyses. Journal of Wildlife Management 65, 373-378.

Antonovics J, van Tienderen PH. 1991 Ontoecogenophyloconstraints? The chaos of constraint terminology. Trends in Ecology \& Evolution 6, 166-168. (doi: 10.1016/0169-5347(91)900597)

Austad SN. 1993 Retarded senescence in an insular population of Virginia opossums (Didelphis virginiana). Journal of Zoology 229, 695-708. (doi: 10.1111/j.1469-7998.1993.tb02665.x)

Baudisch A, Vaupel JW. 2012 Getting to the root of aging. Science 338, 618-619. (doi: 10.1126/science.1226467)

Berven KA, Gill DE. 1983 Interpreting geographic variation in life history traits. American Zoologist 23, 85-97. (doi: 10.1093/icb/23.1.85) 
Cayuela H, Besnard A, Cote J, Laporte M, Bonnaire E, Pichenot J, Schtickzelle N, Bellec A, Joly P, Lena JP. 2019b. Anthropogenic disturbance drives dispersal syndromes, demography, and gene flow in spatially structured amphibian populations. bioRxiv 789966 . (doi: https://doi.org/10.1101/789966)

Cayuela H, Olgun K, Angelini C, Uzum N, Peyronel O, Miaud C, Avci A, Lemaitre JF, Schmidt BR. 2019c. Slow life-history strategies are associated with negligible actuarial senescence in western Palearctic salamanders. Proceedings of the Royal Society B, 286, 0191498. (doi: 10.1098/rspb.2019.1498)

Cayuela H, Akani GC, Hema EM, Eniang EA, Amadi N, Ajong SN, Dendi D, Petrozzi F, Luiselli L. 2019d. Life history and age-dependent mortality processes in tropical reptiles. Biological Journal of the Linnean Society, 128, 251-262. (doi: 10.1093/biolinnean/blz103)

Cayuela H, Cruickshank SS, Brandt H, Ozgul A, Schmidt BR. 2019d. Habitat-driven life history variation in an amphibian metapopulation. Oikos, 128, 1265-1276. (doi: 10.1111/oik.06286)

Colchero F, Clark JS. 2012a. Bayesian inference on age-specific survival for censored and truncated data. Journal of Animal Ecology 81, 139-149. (doi: 10.1111/j.13652656.2011.01898.x)

Colchero F, Jones OR, Rebke, M. 2012b BaSTA: an R package for Bayesian estimation of agespecific survival from incomplete mark-recapture/recovery data with covariates. Methods in Ecology and Evolution 3, 466-470. (doi: 10.1111/j.2041-210X.2012.00186.x)

Colchero F, Jones OR, Conde DA, Hodgson D, Zajitschek F, Schmidt BR, Malo AF, Alberts SC, Becker PH, Bouwhuis S, Bronikowski AM, De Vleeschouwer KM, Delahay RJ, Dummermuth S, Fernandez-Duque J, Frisenvaenge J, Hesselsoe M, Larson S, Lemaître JF, McDonald J, Miller DAW, O’Donnell C, Packer C, Raboy BE, Reading CJ, Wapstra E, Weimerskirch H, While GM, Baudisch A, Flatt T, Coulson T, Gaillard JM. 2019. The diversity of population responses to environmental change. Ecology Letters 22, 342-353. (doi: 10.1111/ele.13195)

de Kroon H, Van Groenendael J, Ehrlén, J. 2000. Elasticities: a review of methods and model limitations. $\quad$ Ecology, $\quad 81, \quad 607-618 . \quad$ (doi: $\quad$ 10.1890/00129658(2000)081[0607:EAROMA]2.0.CO;2)

Gaillard JM, Lemaitre JF, Berger V, Bonenfant C, Devillard S, Douhard M, Gamelon M, Plard F, Lebreton JD. 2016 Axes of variation in life histories. The Encyclopedia of Evolutionary Biology, Elsevier, pp. 312-23.

Gaillard JM, Lemaitre JF. 2017 The Williams' legacy: A critical reappraisal of his nine predictions about the evolution of senescence. Evolution 71, 2768-2785. (doi: 10.1111/evo.13379) 
Massot M, Clobert J, Montes-Poloni L, Haussy C, Cubo J, Meylan S. 2011 An integrative study of ageing in a wild population of common lizards. Functional Ecology 25, 848-858. (doi: 10.1111/j.1365-2435.2011.01837.x)

Medawar PB. 1952 An unsolved problem of biology. London, UK, H.K. Lewis.

Moorad J, Promislow D, \& Silvertown J. 2019. Evolutionary Ecology of Senescence and a Reassessment of Williams' 'Extrinsic Mortality' Hypothesis. Trends in Ecology \& Evolution, 34, 519-530. (doi: 10.1016/j.tree.2019.02.006)

Morrison C, Hero JM. 2003 Geographic variation in life-history characteristics of amphibians: a review. Journal of Animal Ecology 72, 270-279. (doi: 10.1046/j.1365-2656.2003.00696.x)

Nevoux M, Forcada J, Barbraud C, Croxall J, Weimerskirch H. 2010 Bet-hedging response to environmental variability, an intraspecific comparison. Ecology 91, 2416-2427. (doi: 10.1890/09-0143.1)

Nilsen EB, Gaillard JM, Andersen R, Odden J, Delorme D, Van Laere G, Linnell JD. 2009 A slow life in hell or a fast life in heaven: demographic analyses of contrasting roe deer populations. Journal of Animal Ecology 78, 585-594. (doi: 10.1111/j.1365-2656.2009.01523.x)

Nussey DH, Froy H, Lemaitre JF, Gaillard JM, Austad SN. 2013 Senescence in natural populations of animals: widespread evidence and its implications for bio-gerontology. Ageing Research Reviews 12, 214-225. (doi: 10.1016/j.arr.2012.07.004)

Péron G, Gimenez O, Charmantier A, Gaillard JM, Crochet PA. 2010 Age at the onset of senescence in birds and mammals is predicted by early-life performance. Proceedings of the Royal Society of London B, 277, rspb20100530. (doi: 10.1098/rspb.2010.0530)

Pletcher SD. 1999 Model fitting and hypothesis testing for age-specific mortality data. Journal of Evolutionary Biology 12, 430-439. (doi: 10.1046/j.1420-9101.1999.00058.x)

Réale D, Garant D, Humphries MM, Bergeron P, Careau V, Montiglio PO. 2010. Personality and the emergence of the pace-of-life syndrome concept at the population level. Philosophical Transactions of the Royal Society B: Biological Sciences, 365, 4051-4063. (doi: 10.1098/rstb.2010.0208)

Reznick DN, Bryant MJ, Roff D, Ghalambor CK, Ghalambor DE. 2004. Effect of extrinsic mortality on the evolution of senescence in guppies. Nature, 431, 1095-1099. (doi: 10.1038/nature02936)

Ricklefs RE, Scheuerlein A. 2001 Comparison of aging-related mortality among birds and mammals. Experimental gerontology 36, 845-857. (doi: 10.1016/S0531-5565(00)00245-X)

Ricklefs RE. 2010 Life-history connections to rates of aging in terrestrial vertebrates. Proceedings of the National Academy of Sciences, 107, 10314-10319. (doi: 10.1073/pnas.1005862107) 
Tidière M, Gaillard JM, Berger V, Müller DW, Lackey LB, Gimenez O, Clauss M, Lemaître JF. 2016 Comparative analyses of longevity and senescence reveal variable survival benefits of living in zoos across mammals. Scientific Reports 6, 36361. (doi: 10.1038/srep36361)

Turner FB. 1962. The demography of frogs and toads. Quarterly Review of Biology 37, 303-314.

Van Bocxlaer I, Loader SP, Roelants K, Biju SD, Menegon M, Bossuyt F. 2010 Gradual adaptation toward a range-expansion phenotype initiated the global radiation of toads. Science 327, 679682. (doi: 10.1126/science.1181707)

Warner DA, Miller DA, Bronikowski AM, Janzen FJ. 2016. Decades of field data reveal that turtles senesce in the wild. Proceedings of the National Academy of Sciences 113, 6502-6507. (doi: 10.1073/pnas.1600035113)

Warren, SD, Büttner R. 2008 Relationship of endangered amphibians to landscape disturbance. The Journal of Wildlife Management 72, 738-744. (doi: 10.2193/2007-160)

Wells KD. 2010. The ecology and behavior of amphibians. University of Chicago Press, US.

Werner EE. 1986. Amphibian metamorphosis: growth rate, predation risk, and the optimal site at transformation. American Naturalist 128, 319-341.

Williams GC. 1957 Pleiotropy, natural selection, and the evolution of senescence. Evolution 11, 398-411. (doi: 10.1111/j.1558-5646.1957.tb02911.x)

Williams PD, Day T. 2003. Antagonistic pleiotropy, mortality source interactions, and the evolutionary theory of senescence. Evolution, 57, 1478-1488. (doi: 10.1111/j.00143820.2003.tb00356.x)

Williams PD, Day T, Fletcher Q, Rowe L. 2006. The shaping of senescence in the wild. Trends in Ecology \& Evolution 21, 458-463. (doi: 10.1016/j.tree.2006.05.008) 
617 Table 2. Model selection results. Deviance information criterion (DIC) for each of the mortality 618 function considered in the four studied populations of Bombina variegata. We considered the four 619 mortality functions implemented in BaSTA program: exponential (EXP), Gompertz (GOM), 620 Weibull (WEI) and logistic (LOG). For the three last functions, we considered three potential 621 shapes: simple that only uses the basic functions described above ("simple"); Makeham ("make"); 622 and bathtub ("bath").

\begin{tabular}{lllll}
\hline Function & SLOW1 & SLOW2 & FAST1 & FAST2 \\
\hline LOG_simple & 13883.1 & 9770.011 & 6539.856 & 79770.16 \\
LOG_bath & 13408.63 & 9511.085 & $\mathbf{6 1 6 4 . 5 6 8}$ & $\mathbf{7 6 0 3 9 . 0 6}$ \\
LOG_make & 13878.78 & 9706.06 & 6559.085 & 79669.19 \\
EXP & 16151.69 & 11085.02 & 8179.035 & 120984.4 \\
GOM_simple & 13515.9 & 9104.43 & 6859.955 & 91054.45 \\
GOM_bath & $\mathbf{1 3 2 1 0 . 6 7}$ & $\mathbf{8 8 5 5 . 4 6 7}$ & 6797.639 & 89020.97 \\
GOM_make & 13534.36 & 9065.034 & 6888.318 & 91053.47 \\
WEI_simple & 13793.82 & 9451.142 & 6811.184 & 87726.47 \\
WEI_bath & 13406.18 & 9230.966 & 6653.47 & 85057.55 \\
WEI_make & 13790.13 & 9464.459 & 6805.522 & 87757.15 \\
\hline
\end{tabular}



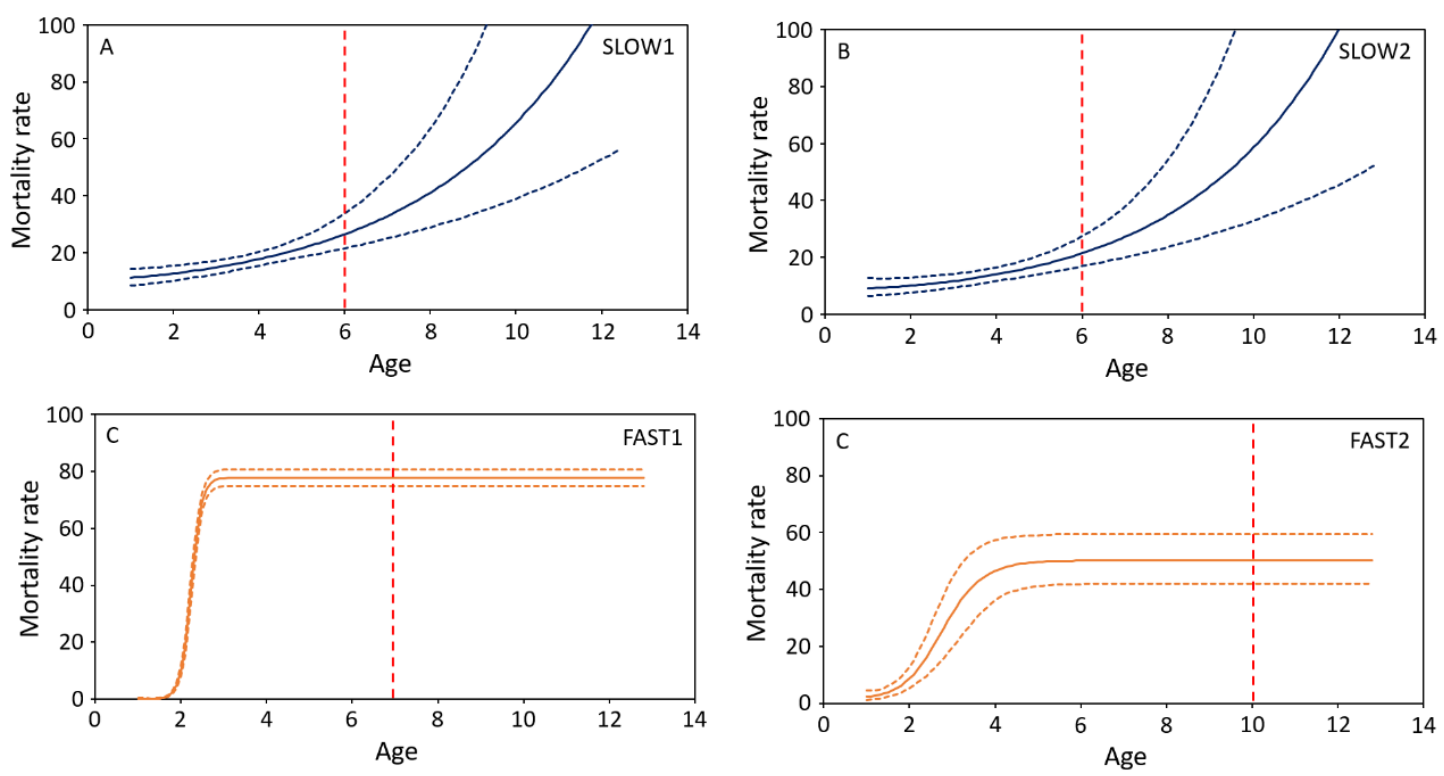

631

Fig. 2. Mortality rate (i.e., proportion of individuals dying at a given age) in two fast (FAST1 and FAST2) and slow (SLOW1 and SLOW2) populations of Bombina variegata. The predictions on the left of the vertical dashed line correspond to observed ages while those on the right are model 635 projections.
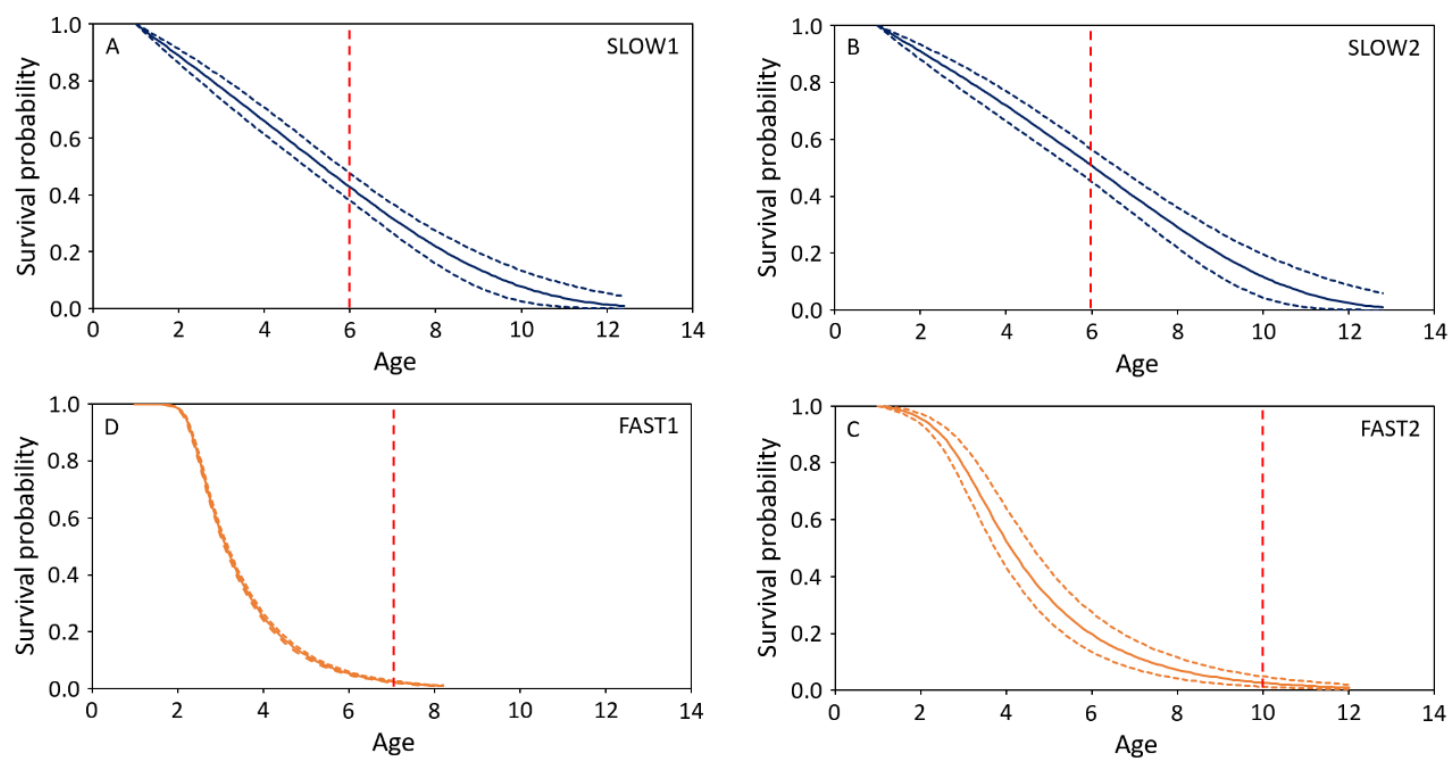

636

637 Fig. 3. Survival probability until a given age in two fast (FAST1 and FAST2) and slow (SLOW1 638 and SLOW2) populations of Bombina variegata. The predictions on the left of the vertical dashed 639 line correspond to observed ages while those on the right are model projections. 